\title{
A filosofia como decifração do enigma do mundo
}

\section{The philosophy as decipherment of the enigma of the world}

\author{
Selma Bassoli \\ Doutora em Filosofia pela Universidade de São Paulo, \\ Membro da Seção Brasileira da Schopenhauer-Gesellschaft \\ E-mail: selma.bass@gmail.com
}

Resumo: Para Schopenhauer, a filosofia consiste em uma reflexão conceitual que nos permite compreender o enigma colocado pela existência inevitável do sofrimento e da morte, através de uma metafísica que ele qualifica como imanente. Por ser imanente, a sua metafísica não deve ser entendida como uma explicação obtida através de um conhecimento situado fora ou além da experiência, pois ela consiste na interpretação que considera os fatos da experiência interna e externa que estão ao alcance de todos e as relações desses fatos com o mundo, através da qual podemos compreender a ligação mais profunda e oculta existente entre eles. Consequentemente sua metafísica não formula conclusões sobre aquilo que está fora de toda a possibilidade de experiência, razão pela qual ela deixa em suspenso todas as questões cujas respostas não podem ser assimiladas por meio das formas e funções do nosso intelecto.

Palavras-chave: Filosofia; Metafísica Imanente; Sofrimento; Schopenhauer.
Abstract: For Schopenhauer, philosophy consists of a conceptual reflection that allows us to understand the enigma posed by the inevitable existence of suffering and death, through a metaphysics that he qualifies as immanent. Because it is immanent, its metaphysics should not be understood as an explanation obtained through a knowledge situated outside or beyond experience, for it consists in the interpretation that considers the facts of the inner and outer experience available to all and the relationships of these facts with the world, through which we can understand the deepest and most hidden connection between them. Consequently his metaphysics does not draw conclusions about whatever is beyond all possibility of experience, and for that reason, it keeps hanging all questions to which answers cannot be assimilated through the forms and functions of our intellect.

Keywords: Philosophy; Immanent Metaphysics; Suffering; Schopenhauer. 
$\mathrm{P}$ ara Schopenhauer, a filosofia tem a sua origem a partir do espanto que podemos sentir com a nossa própria existência e, especialmente, com o conhecimento de que ela é finita e repleta de sofrimentos. Nós nos assombramos com isto porque, em nossa rotina, não consideramos o fato de que iremos morrer e de que nossas ações são motivadas pela fuga da dor inerente à vida. 0 que predomina em nossa consciência é o prazer que buscamos incessantemente e que se caracteriza pela supressão momentânea do nosso sofrimento, sem nos darmos conta de que jamais conseguiremos alcançar uma satisfação plena e duradoura.

A possibilidade de modificarmos a nossa consciência através do sentimento de espanto decorre do fato de possuirmos razão; por isto, apenas o ser humano pode sentilo e, segundo Schopenhauer, "mesmo a pessoa mais inculta e tacanha se torna vividamente consciente em seus momentos mais lúcidos"1. Porém, quanto mais brilhante e mais reflexiva for uma consciência, mais essas questões estarão nela presentes de maneira distinta e permanente ${ }^{2}$, o que nos permite estabelecer uma relação entre a capacidade reflexiva e o grau de consciência, através da qual podemos constatar que quanto maior for o desenvolvimento da capacidade de refletir, maior será a consciência sobre a inevitabilidade do sofrimento e a finitude da existência.

Essa relação fica mais clara quando consideramos que a razão, por nos proporcionar a capacidade de refletir, nos permite ter ações planejadas - com base não só no presente, mas também no passado e no futuro - que nos oferecem uma visão de conjunto da vida e do curso do mundo. Mas, por outro lado, Schopenhauer afirma que a atividade da razão é dependente do intelecto, pois, para formar conceitos por meio de abstrações, a razão depende das representações intuitivas fornecidas por ele. Além disso, ele defende que os animais irracionais também possuem um intelecto e, consequentemente, eles são igualmente considerados seres dotados de consciência e da capacidade de conhecer os objetos que promovem seus sentimentos de bem-estar ou mal-estar. 0 conhecimento que o intelecto tem dos objetos, com a finalidade de promover a satisfação da vontade, é, portanto, semelhante nos homens e nos animais. A diferença está em que a vontade humana não é satisfeita ou motivada apenas por objetos que são percebidos diretamente pelo intelecto; pois a capacidade de abstração, proveniente da razão, atua no conhecimento do homem e permite que ele seja motivado

${ }^{1}$ SCHOPENHAUER, A. MVR II, p. 263.

2 Ibidem.

A filosofia como decifração do enigma do mundo 
por lembranças do passado ou por antecipações futuras, ou, até mesmo, por eventos imaginados, o que torna a satisfação da sua vontade um processo mais complexo do que aquele que envolve a satisfação da vontade dos seres irracionais.

A reflexão e a abstração proporcionadas pela razão permitem que o homem leve em conta outros motivos além daqueles que ele percebe imediatamente, visto que a deliberação que precede a ação humana envolve pensamentos e conceitos; elas também permitem que o homem estabeleça relações entre pensamentos e conceitos, as quais se distanciam cada vez mais da finalidade de satisfazer a vontade. A razão tem, portanto, dois modos de atuar no conhecimento: por um lado, ela auxilia o intelecto a satisfazer a vontade, fornecendo a ela motivos constituídos por abstrações que, entretanto, só podem ser obtidas a partir das intuições do intelecto; mas, por outro lado, ela proporciona, através das relações entre os motivos, um tipo de conhecimento que favorece o distanciamento do intelecto da sua função de satisfazer a vontade. Matthias Kossler fornece um exemplo que ilustra o processo de aquisição desse modo de conhecimento:

\begin{abstract}
ao subir uma montanha, pode ser que surja a ideia de permanecer no topo atuando como motivo e, como contra-motivo, a ideia do perigo da queda; ambos os motivos permanecem em referência imediata à minha vontade. Eu posso então também me perguntar se o belo sentimento que eu ligo à visão do topo estaria relacionado com o fato de eu ter vencido o perigo. Essa reflexão ainda permanece em relação com a minha vontade, mas de modo apenas mediato. Por fim, posso chegar a me perguntar, de modo bem geral e sem qualquer relação com aquilo que eu quero ou não quero, se toda felicidade resulta de um perigo vencido e nada mais é que a mera negação do sofrimento ${ }^{3}$.
\end{abstract}

A ideia de felicidade como negação do sofrimento, obtida através da reflexão que relaciona pensamentos e percepções, mostra como a razão permite uma maneira de pensar que se desliga progressivamente do conhecimento destinado à satisfação vontade, conferindo objetividade ao modo de conhecimento. Essa objetividade não deve ser confundida com o conceito de objeto que, na teoria do conhecimento de Schopenhauer, é definido como objetivação da intuição empírica, quando o entendimento constrói, para uma dada sensação, a sua causa no tempo e no espaço, tornando a intuição algo que se coloca externamente diante do sujeito. Essa intuição é definida por Schopenhauer como uma objetidade inadequada, pois ela não diz respeito

${ }^{3}$ KOSSLER, M. Sobre o papel do discernimento [Besonnenheit] na estética de Arthur Schopenhauer, p. 26. A filosofia como decifração do enigma do mundo 
ao próprio objeto, mas ao objeto como meio de satisfação da vontade e, portanto, ela não é objetiva no sentido da independência da vontade. A objetidade adequada corresponde ao conceito schopenhaueriano de Ideia, que pode ser entendido como o resultado da soma de todas as relações que constituem o caráter de uma coisa ${ }^{4}$ e corresponde ao modo de percepção que apreende a natureza essencial de um objeto. A Ideia é o modo de conhecimento que é próprio ao gênio artístico, pois as coisas particulares não constituem o seu objeto propriamente dito:

Ver o universal no particular é sempre precisamente a característica fundamental do gênio, enquanto o homem normal reconhece de modo específico apenas as coisas particulares, pois a efetividade só lhe interessa no que faz referência à sua própria vontade [...] De acordo com isto, o verdadeiro objeto do gênio é apenas a natureza essencial das coisas em geral, o universal em si, a totalidade 5 .

A apreensão da natureza essencial das coisas exige do gênio uma clareza de consciência [Besonnenheit] decorrente de um alto grau de reflexão. Essa clareza caracteriza não só o conhecimento do gênio, mas também o do filósofo, visto que ambos podem apreender objetivamente o mundo através de um modo de conhecimento que é independente da relação com a vontade. Entretanto, se a clareza de consciência é uma característica comum a eles, o modo de alcançá-la é específico para cada um deles, pois o gênio alcança a clareza de consciência mediante o conhecimento do caráter de uma coisa, enquanto o filósofo a alcança mediante o conhecimento de sua essência ${ }^{6}$.

A diferença entre o conhecimento do caráter e o da essência de uma coisa tornase mais clara quando se considera a distinção que Schopenhauer estabelece entre o conhecimento da Ideia e o da essência da coisa-em-si, visto que a Ideia ainda não é a essência em si mesma, mas apenas a expressão completa de um objeto, que determina o conjunto de suas relações:

\footnotetext{
${ }^{4} \mathrm{Cf}$. SCHOPENHAUER, WWV II, p. 432 apud KOSSLER. M. Sobre o papel do discernimento [Besonnenheit] na estética de Arthur Schopenhauer, p. 27.

${ }^{5}$ SCHOPENHAUER, A. MVR II, p. 35-36.

${ }^{6}$ É importante considerar que a clareza de consciência também é comum ao santo, visto que este, assim como o filósofo, é capaz de conhecer a essência das coisas. Porém o santo diferencia-se do filósofo, pois este conclui a essência das coisas enquanto o santo a intui. Para obter a conclusão sobre a essência do mundo, considerando-a como uma unidade da qual os fenômenos são a manifestação empírica, o filósofo relaciona pensamentos e conceitos e conecta a experiência externa com a interna. 0 santo, por sua vez, alcança a intuição da essência das coisas de um modo imediato, quando ocorre uma mudança completa na forma usual de conhecimento, a qual pressupõe a vivência prévia e intensa do sofrimento.

A filosofia como decifração do enigma do mundo
} 
Ideia na verdade ainda não é a essência da coisa-em-si mesma, mesmo porque ela surge do conhecimento de meras relações; mas ela é, como o resultado da soma de todas as relações, o caráter propriamente dito da coisa, e com isso, a expressão completa da essência que se apresenta à intuição como objeto, compreendida não em relação a uma vontade individual, mas como ela mesma se expressa a si mesma e por meio do que determina o conjunto de suas relações, que unicamente eram conhecidas até aqui ${ }^{7}$.

A Ideia também se diferencia da intuição comum, pois nesta apenas um lado do objeto é apreendido, ou seja, aquele que interessa à vontade. A intuição artística só surge quando todos os outros lados são apreendidos por meio da fantasia do artista. Segundo Schopenhauer, o artista utiliza a fantasia "não para ver nas coisas o que a natureza efetivamente imaginou, mas aquilo que ela se esforçou para formar, mas devido à [...] luta de suas formas entre si, não chegou a realizar"8.

O significado do termo caráter, quando aplicado ao indivíduo, contribui para a compreensão do seu significado quando aplicado à Ideia de uma coisa. Pois, assim como o caráter de um indivíduo determina as suas ações e, inversamente, o conjunto de todas as ações de um indivíduo permite saber a constituição do seu caráter, o caráter de uma coisa determina as relações que podem se desdobrar a partir dessa coisa, e, inversamente, o conjunto de todas as relações que provêm de uma coisa permite conhecer a constituição do seu caráter. Ao apreender a Ideia de uma coisa, o gênio conhece o caráter a partir do qual ele pode fornecer, inclusive através da imaginação, o conjunto das relações que pertencem a essa coisa. Segundo Kossler:

Se as relações são consideradas apenas como desdobramento das ideias, então elas não são determinadas a partir do que lhe é alheio, especialmente da vontade do observador, mas, como manifestação da essência de uma coisa,são independentes disso, assim como o caráter de um homem cunha suas ações independente das circunstâncias em que elas se dão9.

A partir da distinção entre a Ideia e a essência de uma coisa, podemos compreender a diferença existente entre a clareza de consciência que se manifesta no

\footnotetext{
7 SCHOPENHAUER, WWV II, p. 432 apud KOSSLER. M. Sobre o papel do discernimento [Besonnenheit] na estética de Arthur Schopenhauer, p. 27.

${ }^{8}$ SCHOPENHAUER, A. WWV I, p. 241 apud KOSSLER, M. Sobre o papel do discernimento [Besonnenheit] na estética de Arthur Schopenhauer, p. 51.

${ }^{9}$ KOSSLER, M. Sobre o papel do discernimento [Besonnenheit] na estética de Arthur Schopenhauer, nota 37, p. 27-28.

A filosofia como decifração do enigma do mundo
} 
gênio e aquela que se manifesta no filósofo. No gênio, essa clareza surge na apreensão da Ideia de um objeto, a partir da qual ele pode mostrar as relações desse objeto com as outras coisas. Já a clareza de consciência no filósofo é obtida através da relação entre pensamentos e conceitos e permite que ele apreenda a essência das coisas. Para apreender essa essência, o filósofo procede, por assim dizer, no sentido inverso ao do gênio, pois o gênio parte do caráter da coisa para as suas relações, enquanto o filósofo parte das relações para a essência da coisa ${ }^{10}$. 0 procedimento que vai das relações em direção à essência é intermediado por uma atividade semelhante à do cientista, visto que este procura identificar regularidades no plano empírico, a fim de formar conceitos gerais:

A filosofia chega desse modo primeiro apenas a um conceito geral do modo de ação das coisas, não porém a uma compreensão intuitiva da essência, que conduziria à adoção da perspectiva da coisa. 0 número de relações consideradas de uma coisa sem a força criativa da fantasia permanece limitada, e da mesma forma o conceito diante da ideia é abstrato Até esse ponto, isso corresponde ao procedimento da ciência que identifica empiricamente regularidades e as atribui nomes abstratos de forças ${ }^{11}$.

A diferença entre o filósofo e o cientista é que, no filósofo, a formação de conceitos é complementada pelo conhecimento da própria vontade, quando, através da atividade reflexiva, o filósofo conecta o conhecimento objetivo, externo, decorrente do modo de atuar das coisas, à experiência subjetiva, interna, decorrente do conhecimento da sua própria vontade:

Na filosofia de Schopenhauer essa observação conclusiva inicialmente externa é completada por meio da experiência da própria essência como vontade. Essa experiência primeiramente subjetiva da autoconsciência imediata é ligada, por meio da reflexão, ao conhecimento do modo de atuar das coisas, e dessa forma a vontade, isto é, aquilo "que em nós chamamos vontade", é conhecida como aquilo que é a essência do mundo e que está na base de todos os fenômenos e ideias ${ }^{12}$

A filosofia se caracteriza pela atividade que alcança o conhecimento da essência do mundo de modo discursivo, ou seja, por meio de formulações conceituais organizadas

${ }^{10} \mathrm{Cf}$. Idem, p. 31.

11KOSSLER, M. Sobre o papel do discernimento [Besonnenheit] na estética de Arthur Schopenhauer, p. 31-32.

12 Ibidem.

A filosofia como decifração do enigma do mundo 
em etapas sucessivas e logicamente encadeadas, que conecta a experiência externa à interna, formando uma unidade metafísica, a partir do conhecimento do conjunto da experiência. A conexão entre a experiência interna e a externa acontece por meio da reflexão que, ao fornecer uma interpretação do mundo, alude à sua essência metafísica, ao mesmo tempo em que preserva a imanência dos seus fenômenos. A preservação do aspecto imanente da explicação metafísica ocorre seja através da fonte empírica que dá origem à reflexão, seja através da exigência de que essa interpretação metafísica tenha uma comprovação empírica.

O conhecimento filosófico se caracteriza pela objetividade proveniente da clareza de consciência, que só pode ser obtida por meio da racionalidade que é própria dos seres humanos. Porém nem todo homem alcança a clareza de consciência que a filosofia exige. A consciência do homem comum, embora não seja idêntica à dos animais, é de característica aparentada, pois também a sua apreensão das coisas e do mundo é predominantemente subjetiva e imanente, pois o seu conhecimento também está direcionado apenas à satisfação da vontade. Portanto, também para a maioria dos homens o conhecimento objetivo tem um fundamento subjetivo, no sentido de que é a vontade que determina o fim daquilo que é conhecido.

A imanência atribuída ao conhecimento da maioria dos homens está no fato de que, apesar de possuírem a racionalidade que lhes proporciona a capacidade de refletir, eles não desenvolvem essa capacidade suficientemente, o que limita o poder de suas consciências e os impede de ultrapassar o conhecimento ordinário, tornando-os incapazes de realizar o questionamento sobre a razão de ser das coisas que caracteriza o conhecimento filosófico. Por causa da limitação da sua consciência, o homem comum percebe as coisas do mundo, mas não o mundo; seu próprio agir e sofrer, mas não a si mesmo. O grau de desenvolvimento do intelecto está relacionado ao grau de desenvolvimento da consciência e este, por sua vez, depende do grau da atividade reflexiva proveniente da razão. Assim, quanto maior for a atividade reflexiva, maior será o conhecimento objetivo do intelecto, ou seja, o conhecimento que não se limita à satisfação da vontade, sendo apenas este tipo de conhecimento que proporciona a reflexão filosófica e as explicações metafísicas do mundo. Nesse sentido, Schopenhauer afirma: 
Quanto menos expressiva for uma pessoa do ponto de vista intelectual, menos a existência lhe será enigmática. Pelo contrário, lhe parecerá natural que tudo seja como é, e isto resulta do fato de que o seu intelecto ainda não superou o seu destino originário como serviçal da vontade, como mediador entre esta e os motivos, estando, portanto, firmemente atado ao mundo e à natureza, como uma parte integrante deles. Portanto está muito distante de compreender o mundo de modo puramente objetivo, destacando-se, por assim dizer, da totalidade das coisas. Pelo contrário, o espanto filosófico que surge disso é condicionado no indivíduo pelo alto desenvolvimento da inteligência, embora geralmente não por isto apenas. Mas, indubitavelmente, é o conhecimento da morte, e com isso a consideração dos sofrimentos e da miséria da vida, o que dá o impulso mais forte à reflexão filosófica e às explicações metafísicas do mundo ${ }^{13}$.

A importância do sofrimento está em que ele favorece a reflexão que remete à explicação metafísica do mundo, capaz de nos fazer compreender que o sofrimento não nos acontece por acaso, pois ele é algo intrínseco à existência e que, portanto, não há vida sem sofrimento. Esse modo de compreender a vida não é normalmente apreendido, pois, no processo de afirmação da vontade, através do quala vida se mantém, cada uma de nossas ações visa obter oprazer ou a fuga da dor. Por causa disso, toda ação acontece com base em uma ilusão, pois o sofrimento é considerado algo ocasional e que pode ser evitado, quando, na verdade, ele é inerente à vida.

Ao considerarmos o modo ilusório através do qual a vida se manifesta, o sofrimento adquire importância por estimular a percepção do verdadeiro significado da existência. Este significado não é facilmente apreendido, pois ele está oculto sob o modo como afirmamos a vida, cuja particularidade é a busca incessante do prazer. Esse aspecto oculto é o que confere um caráter metafísico à explicação filosófica do mundo. Schopenhauer define o conhecimento metafísico como

Todo suposto conhecimento que vai além da possibilidade da experiência e, portanto, para além da natureza ou da aparência das coisas dadas, a fim de fornecer explicações sobre as razões que, em um sentido ou outro, a experiência é condicionada, ou, em linguagem popular, sobre o que está escondido por trás da natureza e a torna possível14.

Além de ser um conhecimento metafísico, a filosofia de Schopenhauer é qualificada como imanente. 0 termo imanente significa a permanência dentro dos 
limites da possibilidade da experiência; já o termo transcendente significa o oposto, ou seja, ir além dessa possibilidade. Aparentemente, uma metafísica imanente reúne termos contraditórios, visto que, por ser uma metafísica, a filosofia de Schopenhauer pretende ser um conhecimento que ultrapassa a experiência; porém, por ser imanente, este conhecimento deve permanecer nos limites da experiência. Schopenhauer esclarece que sua metafísica ultrapassa a experiência no sentido de que ela fornece uma interpretação da experiência, que só pode ser obtida quando se considera os seus diversos fenômenos como uma totalidade dotada de coerência. É essa interpretação da totalidade, obtida a partir da conexão entre a experiência externa e interna, que ultrapassa a mera observação das experiências particulares.

A metafísica tradicional pré-crítica, conduzida segundo o princípio de razão suficiente, ultrapassava o campo da experiência com conclusões sobre fundamentos transcendentes. Schopenhauer introduz uma nova maneira de pensar a metafísica, ao considerar que o mundo e as coisas que conhecemos externamente são fenômenos da vontade, que se apresentam através de uma multiplicidade decorrente das formas do espaço, do tempo e da causalidade, que condicionam o modo como conhecemos. Porém, essas formas ocultam, através da multiplicidade, a unidade metafísica que constitui a essência da vontade. Entre a vontade e o modo como ela se manifesta não existe uma relação causal, pois os fenômenos do mundo são a vontade, apenas sob a aparência da multiplicidade. A tarefa da filosofia consiste em explicar a multiplicidade dos fenômenos que compõem o mundo, especialmente aqueles que nos são enigmáticos, pressupondo uma unidade metafísica oculta sob a multiplicidade aparente, que só pode ser conhecida através da supressão das formas que condicionam a realidade empírica.

A necessidade de suprimir essas formas atribui um papel especial à experiência interna, visto que esta forma de conhecimento, por se referir a sentimentos, dispensa a forma do espaço, constituindo a manifestação mais imediata da essência da vontade em nós. A conexão entre essa manifestação interna da vontade e o mundo exterior se dá através das ações, visto que elas são o modo como a nossa vontade pode ser conhecida externamente. Dessa forma, aquilo que experimentamos internamente como prazer e dor constitui uma espécie de ponte que conecta nossas ações e a vontade considerada metafisicamente. Porém essa ponte não fornece um acesso totalmente direto e completo à essência da vontade, mas constitui a chave que torna possível uma interpretação que, 
ao reunir a experiência interna e a externa em uma totalidade, permite decifrar o enigma do mundo, ou seja, compreendê-lo como sendo a manifestação empírica de algo metafísico.

Essa interpretação tem por base um aspecto fundamental da filosofia de Schopenhauer, cuja origem está na doutrina kantiana da coexistência da liberdade e da necessidade - da qual Schopenhauer se apropria para elaborar a sua distinção entre o empírico e o inteligível. Essa distinção permite pensar que a vontade, considerada em si mesma, é uma unidade dotada de liberdade; mas, a partir do momento em que ela se manifesta de modo empírico, o seu ser em si determina de modo necessário, a partir dos motivos, a manifestação da multiplicidade de seus fenômenos, impedindo-a de ser empiricamente diferente. Além disso, ao considerarmos que o empírico é uma manifestação do inteligível, fica estabelecida uma identidade entre dois aspectos de uma mesma coisa, visto que o mundo é a forma como a vontade se torna visível.

Essa identidade metafísica está pressuposta no campo da filosofia moral, pois as ações de uma pessoa constituem o seu caráter empírico e este é considerado a forma de manifestação do seu caráter inteligível. Entretanto, considerando que o caráter empírico se manifesta através de ações cuja visibilidade depende das formas do princípio de razão (tempo, espaço e causalidade), ele jamais poderá expressar perfeitamente o caráter inteligível, pois cada ação só pode representar parcialmente a unidade atribuída a ele, o que torna o conhecimento da vontade a partir do caráter empírico sempre incompleto.

Isto significa que a avaliação moral de um caráter não pode se basear apenas nas ações, pois este seria um modo de avaliação restrito ao caráter empírico ou ao aspecto exterior do caráter. Entretanto, essa avaliação também não pode se basear exclusivamente na forma como os sentimentos são experimentados interiormente, pois a consciência do próprio querer envolve muitos tipos de afetos e paixões, os quais, dependendo de cada indivíduo, podem ser mais fortes ou mais fracos. A solução para o problema da avaliação moral de um caráter está em reunir a experiência externa e a interna, considerando a especificidade da experiência interna, pois os sentimentos constituem um modo privilegiado de acesso ao conhecimento da vontade e fornecem o elo de ligação entre o caráter empírico e o inteligível.

A importância dos sentimentos está em que eles emergem imediatamente na autoconsciência e sinalizam o grau de satisfação ou insatisfação da vontade através das sensações de prazer ou desprazer. Essas sensações podem ser consideradas o 
fundamento do agir, visto que, para Schopenhauer, nenhuma ação acontece sem um motivo suficiente e este motivo sempre se refere ao prazer e ao desprazer, sejam do próprio agente ou de "um outro ser que, portanto, participa da ação passivamente, pois ela acontece para seu dano ou para seu proveito ou alegria"15.

Além disso, as sensações prazer e desprazer- por constituírem o modo mais imediato de manifestação da essência da vontade em um fenômeno percebido internamente - proporcionam a consciência da força primordial do agir. Para a compreensão dessa força, é preciso considerar que tudo o que acontece na natureza tem uma causa e, por outro lado, é a causa de um efeito; o intelecto pode conhecer e esclarecer as causas e os efeitos, mas ele não pode conhecer a força que dá origem à sequência causal. Somente o agir humano pertence a uma espécie de causalidade que permite o conhecimento da sua força originária, ou seja, a vontade como coisa-em-si. Porém, o conhecimento dessa vontade não acontece diretamente como um todo na autoconsciência, mas de um modo fragmentado, através das sensações de prazer e desprazer que motivam tudo o que nós fazemos.

O modo de conhecermos a nossa própria vontade através daquilo que sentimos possui uma particularidade, pois os nossos sentimentos não se situam no espaço; porém o tempo e a relação entre aquele que conhece e aquilo que é conhecido continuam a mediar o autoconhecimento da vontade e explicam porque só podemos conhecê-la a partir de seus atos isolados e sucessivos, não em seu todo, tal como ela é em si e por si. A forma a priori do tempo é o que estabelece o modo sequencial em que se dá o autoconhecimento e, assim, impede a percepção simultânea de várias coisas, visto que, enquanto temos a consciência de algo específico, esquecemos todo o resto, que deixa de existir provisoriamente para nós. Também de acordo com a intermediação do tempo, nós só podemos conhecer imediatamente a nossa vontade enquanto ela é sentida como prazer ou dor ${ }^{16}$. Se essas sensações passam, eu me encontro na mesma situação de uma pessoa que me viu sofrendo, isto é, eu só posso falar indiretamente da minha própria dor. Quando eu tento me recordar da dor que senti, eu me torno um espectador de mim mesmo, na medida em que eu me represento como alguém que já sofreu em determinada circunstância. Essas dificuldades mostram que o autoconhecimento da

15 SCHOPENHAUER, A. Sobre o fundamento da moral, p. 126 (grifos do autor).

${ }^{16}$ Cf. KOSSLER, M. Die Philosophie Schopenhauers als Erfahrung des Charakters, p. 95.

A filosofia como decifração do enigma do mundo 
vontade acontece de um modo fragmentado, impedindo que o julgamento moral possa se basear exclusivamente nele.

A possibilidade de avaliarmos moralmente um caráter está em atribuir-lhe, de modo abstrato, a partir da conexão entre o conhecimento da experiência externa (o caráter empírico) e da experiência interna (os sentimentos), uma unidade metafísica. Esta unidade corresponde ao caráter inteligível e ela é obtida através do estabelecimento de finalidades que caracterizam a maneira de agir de um indivíduo e fazem referência ao seu modo de sentir de prazer em relação ao prazer ou ao desprazer do outro. Schopenhauer divide essas finalidades em três tipos: a busca pelo próprio prazer, a busca pelo prazer do outro e a busca pelo desprazer do outro. De acordo com essas finalidades, podemos julgar os caracteres respectivamente como egoísta, compassivo e malvado. Essas classificações correspondem ao motivo que qualifica moralmente o caráter inteligível, com o qual devem estar de acordo todos os motivos particulares de determinação das ações que constituem o caráter empírico.

A concepção metafísica de caráter inteligível fornece uma explicação sobre as ações e um critério de avaliação moral dos caracteres que têm por base a obtenção do prazer. 0 enigma do mundo inverte essa perspectiva, visto que ele coloca a necessidade de explicaras coisas a partir da existência do sofrimento. Normalmente não se considera que o prazer pressupõe um estado anterior de desprazer, visto que a vontade se manifesta em cada um de nós como um impulso que expressa uma carência originária. Querer algo significa procurar algum objeto que possa suprir essa carência. Dizer como a vontade pode ser satisfeita não esclarece o fato de que ela se constitui como algo que necessita de satisfação, pois deixa-se de considerar que o prazer decorrente da satisfação pressupõe o sofrimento decorrente da carência.

A filosofia de Schopenhauer oferece como resposta ao enigma do mundo o conceito metafísico de vontade, no qual o sofrimento é o seu elemento constitutivo. Com base nesse conceito, podemos compreender que a manifestação empírica da vontade acontece através de uma busca por satisfação, porque a sua essência é um anseio que expressa uma carência fundamental. A carência, considerada como a essência da vontade, faz com que o sofrimento seja inerente à vida e explica porque viver é necessariamente sofrer, mesmo que, empiricamente, a vida se manifeste pela busca incessante do prazer. Ao considerarmos que a essência da vontade é uma carência que gera necessariamente sofrimento, colocamos em evidência o elemento fundamental para 
a decifração do enigma do mundo; pois, mesmo que o mundo seja compreendido como a manifestação da vontade em busca de satisfação, essa manifestação é impulsionada por uma carência que está oculta, mas, sem a qual, o mundo não existiria.

\section{Referências bibliográficas}

KOSSLER, Die Philosophie Schopenhauers als Erfahrung des Charakters. In: Schopenhauer im Komtext. Deutsch-polnisches Schopenhauer-Symposium 2000 (Hrsg. D. Birnbacher/A. Lorenz/L. Miodonski). Würzburg: Königshausen\& Neumann, 2000.

. Sobre o papel do discernimento [Besonnenheit] na estética de Arthur Schopenhauer. In: Eduardo Ribeiro da Fonseca, Fernando Costa Mattos, Flamarion Caldeira Ramos [et al.] (Org.). Dogmatismo e antidogmatismo: Filosofia Crítica, Vontade e Liberdade. Uma homenagem a Maria Lúcia Mello Oliveira e Cacciola. Curitiba: Editora UFPR, 2015.

SCHOPENHAUER, A. O mundo como vontade e representação. Tomo II: Complementos. Trad. Eduardo Ribeiro da Fonseca. Curitiba: Editora UFPR, 2014.

. Sobre o fundamento da moral. Trad. Maria Lúcia Cacciola. São Paulo: Martins Fontes, 1995.

Recebido: $12 / 01 / 18$

Received: 01/12/18

Aprovado: $16 / 01 / 18$

Approved: 01/16/18 